\title{
Use of Processed Electroencephalography in the Clinical Setting
}

\author{
David A. Mulvey ${ }^{1} \cdot$ Peter Klepsch $^{2}$ \\ Accepted: 8 October 2020 / Published online: 23 October 2020 \\ (C) Springer Science+Business Media, LLC, part of Springer Nature 2020
}

\begin{abstract}
Purpose of Review Processed electroencephalography (pEEG) is widely used in clinical practice. Few clinicians utilize the full potential of these devices. This brief review will address the improvements in patient management available from the utilization of all pEEG data.

Recent Findings Anesthesiologists easily learn to recognize raw pEEG patterns that are consistent with an appropriate level of hypnotic effect. Power distribution within the waveform can be displayed in a visual format that identifies signatures of the principal anesthetic hypnotics. Opinion on the benefit of pEEG data in the mitigation of postoperative neurological impairment remains divided. Summary Looking beyond the index number can aid clinical decision making and improve confidence in the benefits of this monitoring modality.
\end{abstract}

Keywords Processed electroencephalography $\cdot \mathrm{pEEG} \cdot$ Bispectral index $\cdot$ BIS $\cdot$ Alpha/delta pattern · Power spectra $\cdot$ Density spectral array $\cdot$ Excessive anesthesia $\cdot$ Postoperative neurological deterioration

\section{Introduction}

Renewed interest in intraoperative processed electroencephalography (pEEG) came with the introduction of the bispectral index (BIS) device in 1996, and numerous other brands have entered clinical practice since. Debate has centered around the displayed index number, what it truly represents and how it may be optimally used [1]. Throughout the lifespan of the BIS device, emphasis has shifted from 'depth of anesthesia,' through 'depth of hypnosis' to 'probability of recall.' No device currently achieves the goal of being an ideal "depth of anesthesia" monitor (Table 1) and predicts the effect of a balanced hypnotic/analgesic approach to patient management. Few professional bodies regard pEEG as an item of

This article is part of the Topical Collection on Patient Safety in Anesthesia

David A. Mulvey

david.mulvey@nhs.net

Peter Klepsch

peter.klepsch@nbt.nhs.uk

1 Department of Anaesthesia, University Hospitals of Derby \& Burton NHS Trust, Uttoxeter Road, Derby DE22 3NE, UK

2 Department of Anaesthesia, North Bristol NHS Trust, Southmead Road, Bristol BS10 5NB, UK mandatory intraoperative monitoring [2-4] and this article will explore the role of pEEG in contemporary practice.

\section{The Index Number}

Given that the index number is not a reliable predictor of response to noxious stimulation, a key goal for $\mathrm{pEEG}$ has been the prevention or reduction in the incidence of accidental awareness under general anesthesia (AAGA) [5]. It is possible that AAGA events represent failure to suppress memory formation [6] as connected consciousness is regularly demonstrated in clinical settings [7] and memory is postulated to be intertwined with appreciation of 'being conscious' [8]. Studies

Table 1 Characteristics of an "ideal" depth of anesthesia device and index

- Tight correlation of index with brain hypnotic concentration

- Clear transitions between conscious and unconscious states

- Guarantees patient is unaware \& amnesic

- Ensures non-paralyzed patient is immobile to noxious stimulation

- Unaffected by use of neuromuscular blockade

- Guides analgesic administration

- Index adjusts to hypnotic/analgesic drugs administered

- Adjusts algorithm for age group 
using BIS guidance show no benefit over a protocol defending end-tidal volatile concentration (EtAA) $\geq 0.7 \mathrm{MAC}_{\text {age }}$ in the maintenance phase of volatile anesthesia $[9,10]$. This raises uncertainty about the value of monitoring the index number, except when compared to AAGA detection using only clinical signs [11]. However, the United Kingdom's National Audit Project 5 (NAP5) reported that only $1 / 3$ of AAGA cases occurred during the maintenance period [12], which questions the role of EtAA alarms at induction and termination of anesthesia. Further studies looking specifically at the utility of pEEG around these timepoints [13] are required before it is relegated from AAGA mitigation during inhalational anesthesia.

The NAP 5 document also reported a twofold increase in the AAGA risk for patients receiving total intravenous anesthesia (TIVA) compared to inhalational maintenance, with the key causative factors being drug errors and lack of training in the safe use of the technique [14]. Consequently, pEEG is recommended during TIVA as a surrogate for continuous delivery of hypnotic to the patient, and the manufacturer's recommended range is sufficiently indicative for this objective [14]. The key benefit of pEEG with TIVA appears to be clinician education when judged by one large observational study [15]. It may be inferred from this paper that anesthesiologists underestimate dosing requirements when administering TIVA by empirical regimens. Half the clinicians in this trial observed the effectiveness/ineffectiveness of their technique (as indicated by BIS) and altered practice subsequently. There was a reduced incidence of AAGA compared to cases without such feedback. Conversely, excessive hypnosis from co-administration of propofol/remifentanil target-controlled infusions is relatively common. This is particularly so in the elderly or frail when easy detection of excessive hypnosis is valuable [16].
Fig. 1 Progressive changes in the raw EEG with increasing concentration of $\mathrm{GABA}_{\mathrm{A}}$ hypnotic agent. A-E show a decrease in frequency and increase in amplitude, followed by burst suppression and an isoelectric line. $\mathbf{C}$ shows the sedated state with alpha and beta oscillations but no delta component; episodes of explicit recall are likely. $\mathbf{D}$ and $\mathbf{E}$ show the onset of slow delta waves and are consistent with appropriate surgical hypnosis ('wind waves riding on the background ocean swell'). (Reproduced with permission from [55]) a Awake with Eyes Open: Beta and Gamma Oscillations

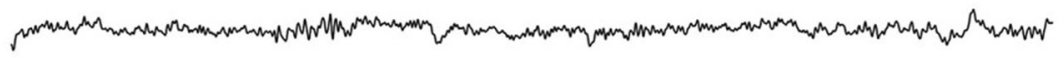

b Paradoxical Excitation: Beta Oscillations

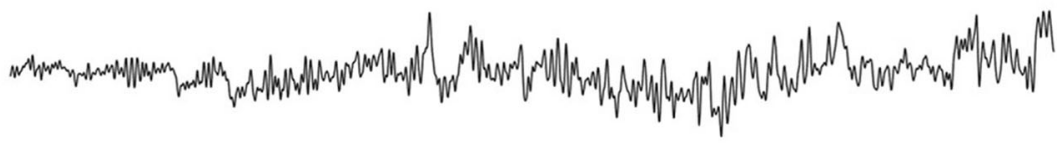

C Sedative State: Alpha and Beta Oscillations

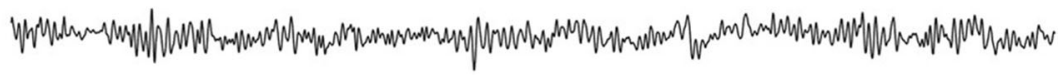

d Unconsciousness at Surgical Level: Slow and Alpha Oscillations

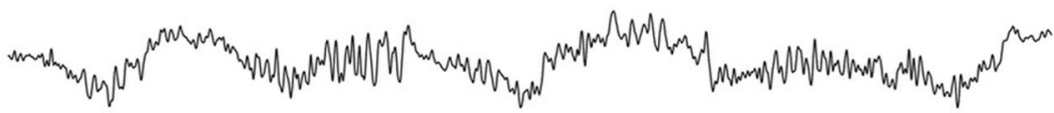

Unconsciousness during Induction: Slow Oscillations

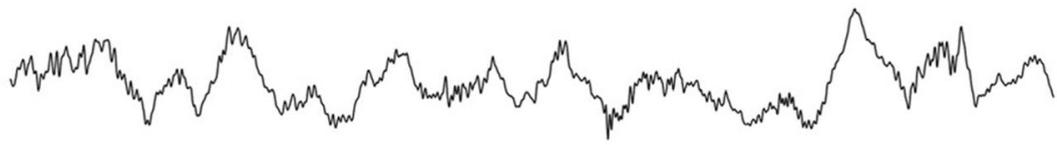

f Unconsciousness: Burst Suppression

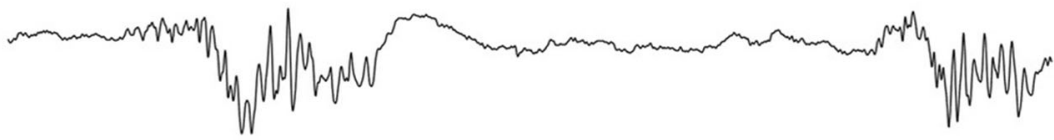

9 Unconsciousness: Isoelectricity

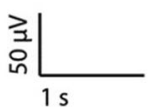


Neuromuscular blockade (NMB) was associated with the highest risk of AAGA in NAP5 irrespective of the hypnotic used and was the commonest factor in cases which resulted in psychological sequelae [12]. Consequently, pEEG is regularly recommended when patients must receive such agents $[12,14,17]$. Muscle activity adjacent to the frontal electrodes can be detected and quantified (electromyography, EMG) and shows overlap with higher frequencies in the pEEG signal [18•]. Some devices include EMG activity in index calculation and may indicate a falsely high index number discordant with the administered hypnotic concentration. Conversely, the use of NMB caused the BIS device to display an 'asleep' index in volunteers who received no hypnotic but were unchallenged by noxious stimulation $[19,20]$. A key feature of the latter study is that raw EEG revealed that the subjects were fully awake. Observation of the train-of-four response when combining NMB and pEEG monitoring seems mandatory if only to remove uncertainty over one possible cause of a changing numerical value. A more comprehensive evaluation of all the raw and processed data provided by the device is warranted when patient management includes paralyzing agents, as emphasized in a recent case report [21] and observational study [22].

Reports are published of connected consciousness (as indicated by a positive response when using the isolated forearm technique, IFT) with both intravenous and inhalational anesthesia despite pEEG indices in the manufacturer's recommended range $[23,24]$. Such reports sap confidence in the technique but probably reflect unrealistic expectations of the capabilities of the device by clinicians [25].

Presently, the focus of pEEG has shifted to the potential for harm by 'too deep' anesthesia [26]. Several studies and metaanalyses report a correlation between the suppression of brain activity by deep hypnosis and postoperative delirium, cognitive decline, or worsened morbidity/mortality [27, 28, 29•, 30]. This is unlikely to be a causal relationship and consequently others report no such association, nor benefit from alerts to this situation $[31,32]$. The reasons for such postoperative morbidity are likely multifactorial and will require a panoply of measures in mitigation $[33,34 \cdot, 35,36]$. Despite little evidence to support $\mathrm{pEEG}$ for this goal $[37,38]$, some professional bodies have recommended its use during anesthesia for particular 'risk' groups [39-42]. Debate continues over the value of pEEG index monitoring [43], but these devices provide at the very least a "window into the brain" and a way to directly observe drug effect on the target organ $[44,45]$.

\section{Beyond the Index Number}

Advances in the understanding of the neurophysiological mechanisms of the principal hypnotic anesthetic agents have been derived from the raw EEG waveform [46]. The anesthesiologist would not expect to interpret heart rate without reference to the electrocardiogram trace, yet clinicians have been conditioned to consider a single number as a representative of the action of their principal drugs. The pEEG index is an oversimplification of information available in the raw EEG and has multiple limitations on its accuracy (environmental artifacts, EMG activity, miscalculation with agents acting via receptors other than $\gamma$-aminobutyric acid type $\mathrm{A}\left(\mathrm{GABA}_{\mathrm{A}}\right)$, anatomical or physiological pathology, and biological age) [18•]. Falsely low or high numbers can be displayed and urge inappropriate action by the clinician, thereby increasing the risk of either AAGA or excessively deep anesthesia [47].
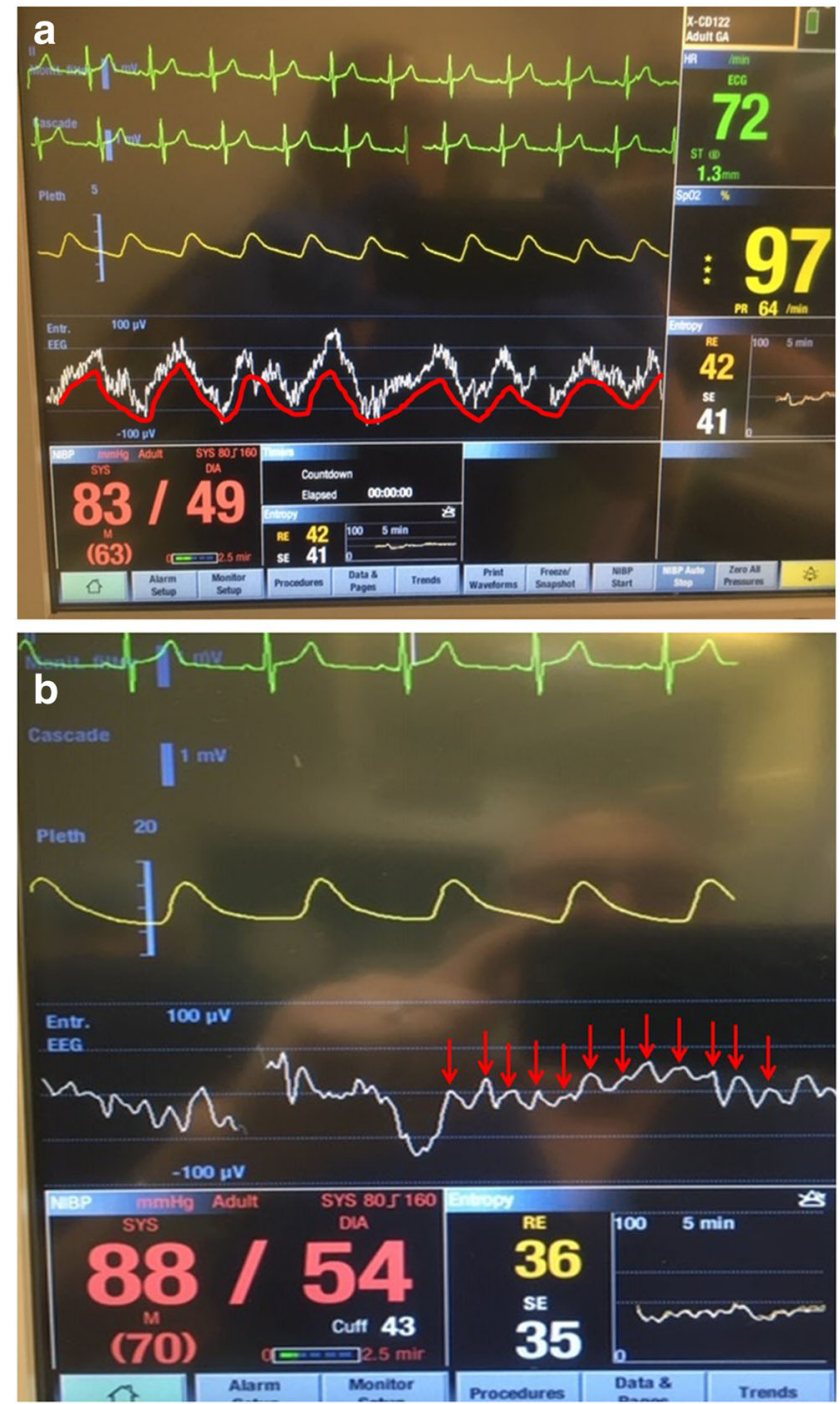

Figure 2 a Appearance of delta waves in a raw pEEG trace. The waveform sweep speed has been slowed to $12.5 \mathrm{~mm} / \mathrm{s}$ and then frozen to facilitate ready observation of this feature. The low-frequency filter must be turned off to see delta waves with the BIS device. To confirm these as delta oscillations, the number of peaks per second of frozen trace (or seconds of trace per peak) should be measured on the screen. b Appearance of alpha waves in a raw pEEG trace. The waveform sweep speed has been increased to $50 \mathrm{~mm} / \mathrm{s}$ before freezing in this instance. To confirm these as alpha oscillations, the number of peaks per second of frozen trace should be measured 
All devices record from electrodes placed over the anterior cranium and display a waveform generated principally by the frontal lobes which is plotted against time. Fast Fourier transformation dissects this waveform into principal component frequencies as the precursor to index number calculation by proprietary algorithms and to derive further parameters such as the power spectrum (PS), density spectral array (DSA), and spectral edge frequency (SEF) [48]. The principal frequency components are classified as gamma $(>30 \mathrm{~Hz})$, beta $(13-$ $30 \mathrm{~Hz})$, alpha $(7-13 \mathrm{~Hz})$, theta $(3.5-7 \mathrm{~Hz})$, and delta $(0.5-$ $3.5 \mathrm{~Hz}$ ) waves and are believed to represent activity in specific neural networks or cortical assemblies. Interpretation of the raw $p E E G$ waveform is helpful in decision making when the index value seems inappropriate for the clinical status of the patient and delivered hypnotic concentration $[47,49,50 \bullet, 51$, $52 \bullet \cdot]$. The appearance and combination of waveforms are characteristics of different stages of altered consciousness and may be used to track the activity of centrally acting anesthetic agents [53, 54]. In general, there is increasing power in the slower frequency bands as the concentration of $\mathrm{GABA}_{\mathrm{A}}$ receptor hypnotic rises and the presence of beta or gamma frequencies is associated with an inadequate level of effect.

Visual inspection of the raw waveform when the patient is awake reveals a high-frequency-low-amplitude pattern, which shifts via a low-frequency-high-amplitude pattern when appropriately anesthetized, to episodes of flat trace alternating with bursts of activity (burst suppression, BS) and ultimately onto an isoelectric line (Fig. 1). These latter phenomena may share a common etiology with the development of postoperative neurocognitive impairment and should act as warning signs [35], although others have suggested a 'cerebral protection' role for these states of hypnosis [16]. Several studies have shown that even 'naïve' anesthesiologists can acquire waveform recognition skills relatively quickly, reflecting the profession's expertise in pattern recognition $[56,57,58 \cdot 0]$. The target pattern for frontal EEG waveforms at an appropriate level of hypnosis is dominated by alphadelta oscillations and easily recognized by comparison to motion of the ocean surface. Delta waves undulate around the baseline, represent the background ocean swell (Fig. 2a), and are generated by the intrinsic rhythm of thalamocortical neurons. Alpha waves 'ride' on the delta waves and are comparable to white foam wind waves (Fig. 2b) generated by a pacemaker activity in thalamic reticular nuclei and thalamocortico-thalamic circuits. Alpha waves are held to be sensitive to noxious events and disappear when such stimulus is applied, returning after administration of adequate analgesia [54]. Theta waves are present at low power during propofol anesthesia but are more evident during hypnosis maintained with halogenated ethers. Beta waves generally indicate light hypnosis when accompanied by delta waves, but if the latter are absent a beta dominant pattern suggests sedation only rather than an adequate level of hypnosis for surgery.

Caveats exist using the alpha/delta pattern as a marker of appropriate hypnotic effect. Alpha power generated by $\mathrm{GABA}_{\mathrm{A}}$ receptor anesthesia becomes less pronounced as patients age (Fig. 3) and may be difficult to identify in patients older than 80 years [59-61]. Connected consciousness as indicated by a positive IFT response has been reported despite the presence of a prominent frontal alpha-delta pattern [62]. Adjunctive analgesia or sedation provided by nitrous oxide, ketamine, or dexmedetomidine may 'contaminate' the raw waveform and make the optimum pattern less obvious $[18 \bullet, 50 \bullet]$.
Fig. 3 Changes in the DSA spectrum of frontal EEG for sevoflurane (top) and propofol (bottom) with age. Relative power is color-coded as per the $\mathrm{dB}$ scale. The $Y$ axis is frequency $(\mathrm{Hz})$ and the $X$ axis is age (years). A decrease in alpha power (8$12 \mathrm{~Hz}$ ) generated by each of the agents is seen with increasing age. The agent 'signatures' are demonstrated also. Propofol has two bands of high power in the alpha and delta ranges, whereas sevoflurane shows the typical "fill-in" effect due to high power in the theta band $(5-7 \mathrm{~Hz})$. Reproduced with permission from reference [59])

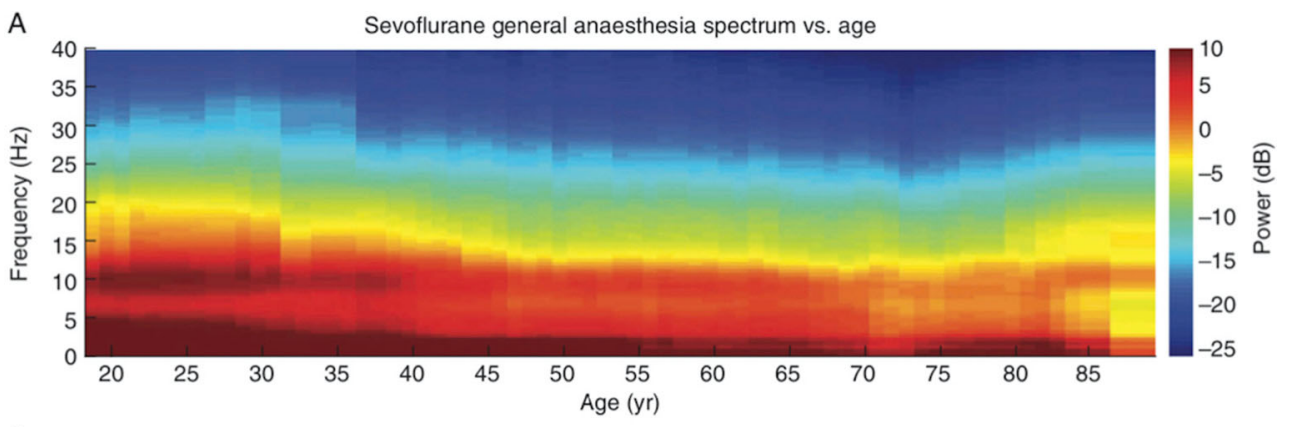

A

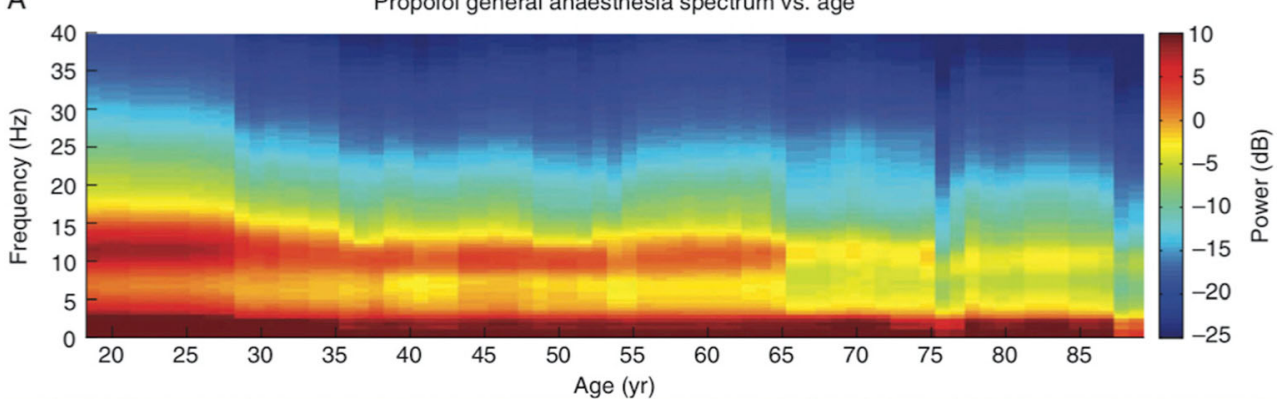


Analysis of the relative power distribution within the pEEG waveform can contribute to decision making. A power spectrum display reveals the comparative activity within the five key frequency bands. If appropriate hypnosis has been achieved with propofol, two characteristic peaks are seen in the alpha and the delta bands, with inclusion of power in the theta band for halogenated ethers. This is easy to visualize if compared to the profile of a cycle race mountain stage (Fig. 4a).

Power distribution can also be summarized and presented as the numerical frequency below where $50 \%$ (median) and
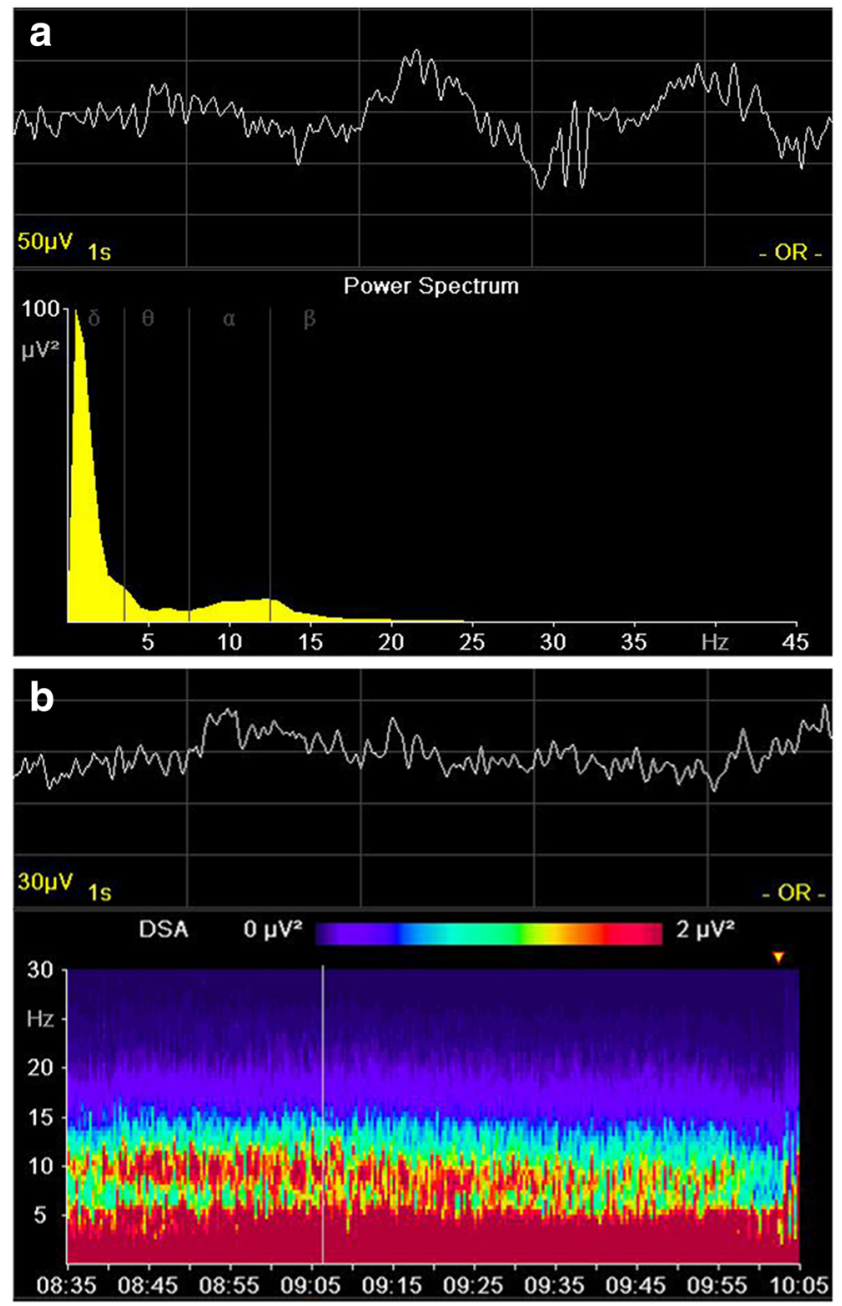

Fig. 4 a Visual presentation of pEEG power distribution between five principle frequency bands and the accompanying simultaneous raw waveform for a subject receiving propofol/remifentanil TIVA. Notable power peaks are seen in the alpha and delta regions, consistent with appropriate hypnosis from this mode of anesthesia. Scale of the $X$ and $Y$ axes for the raw waveform are respectively $1 \mathrm{~s}$ and $50 \mu \mathrm{V}$ per graticule. $\mathbf{b}$ Visual presentation of pEEG power as a density spectral array and the accompanying simultaneous raw waveform (marked by the vertical white line) for a subject receiving propofol/remifentanil TIVA. High-power tracts are seen in the alpha and delta regions, consistent with appropriate hypnosis from this mode of anesthesia. Power is colorcoded as per the displayed scale, and the $X$ axis represents the time of day. Scales of the $X$ and $Y$ axes for the raw waveform are respectively $1 \mathrm{~s}$ and $30 \mu \mathrm{V}$ per graticule
95\% (spectral edge frequency, SEF) of the total power are present. The pattern consistent an alpha/delta appearance of the raw trace shows the median point in the delta band and SEF within the alpha band.

The density spectral array (DSA) is potentially the most useful of the visual graphical analyses [50•]. Power is colorcoded (from red $=$ high to blue $=$ low) and combined with an $X-Y$ diagram of time vs. frequency. Red linear tracks representing high power in alpha and delta frequencies are painted across the time axis when propofol or halogenated ether achieves an appropriate concentration (Fig. 4b). Excellent descriptions of the utility of DSA are available [52••]. Unique 'signatures' are observed for anesthetic agents acting principally at $\mathrm{GABA}_{\mathrm{A}}, \mathrm{N}$-methyl-D-aspartate, and alpha-2 receptors and explain the discrepancies experienced using the latter two agents with 'standard' $\mathrm{pEEG}$ indices [50•]. Changes of cerebral neurophysiology with advancing age are reflected in the DSA trace as a diminution of power in the alpha band during anesthesia [59-61]. This diagnostic advantage of the spectrogram over BIS in the assessment of hypnosis during multimodal anesthesia has been highlighted recently in an interesting case report [21].

Excessive concentrations of hypnotic are recognized by burst suppression (BS) or an isoelectric trace, features seen only with general anesthesia or in pathophysiological circumstances. Burst suppression is a flat trace interrupted by short periods of high amplitude multi-frequency activity and expressed as a percentage of a defined measurement epoch (usually $60 \mathrm{~s}$ ) without this activity. Failure to reduce hypnotic concentration allows BS to progress to a persistent isoelectric state. Although more common in elderly patients, BS may occur unexpectedly in biologically young subjects who have a 'physiologically' old brain. The concentration of hypnotic at which suppression commences is suggested as a marker of patient sensitivity to hypnotics and of propensity for postoperative neurological sequelae [63•]. The importance of this association/causation is debated [38, 64]. The authors of a recent meta-analysis [65] did not find an advantage for pEEG in the prevention of such deterioration, but they emphasized that their findings were heavily influenced by the negative results of the ENGAGES study [66], which has itself attracted critique [67]. Until further data become available, it seems appropriate to target the avoidance of BS or an isoelectric state as a more meaningful use of pEEG rather than achieving a "depth of anesthesia" [50, 51, 52••].

\section{Future Trends}

Processed EEG is an important sensor for closed-loop anesthesia delivery systems. When combined with total intravenous anesthesia, improved control of hypnotic effect has been shown and resulted in shorter recovery times, savings in hypnotic costs, and 
a possible lessening of postoperative neurological impairment $[68,69]$. Few anesthesia workstations provide the facility for feedback control of inhalational concentration by $\mathrm{pEEG}$ and such studies are eagerly awaited.

Monitoring of sedation levels by pEEG in critical care environments was proposed recently as a rational method for managing limited pharmaceutical resources during the COVID-19 pandemic [70]. However, a meta-analysis of data from studies in more controlled circumstances found no benefit of BIS monitoring on clinical outcomes or resource utilization [71]. Continuous EEG monitoring placed and interpreted by a neurophysiologist has utility in critical care practice for diagnosis and prognosis in a range of clinical conditions. Caution has been urged when using processed EEG devices for applications other than sedation monitoring in this environment [72].

\section{Summary and Conclusion}

No monitoring device directly influences safety or outcome. The onus remains with the anesthetic provider to use all information available and steer their actions in a 'best practice' direction. Oversimplification of pEEG monitoring to a single number has raised more questions than it answering and creating uncertainty about its benefit. Understanding the different components of pEEG monitoring allows a comprehensive and nuanced interpretation of the data and a firmer base for clinical decision making, although the underpinning science requires further clarification by appropriately powered studies. Further refinements in signal acquisition and calculation algorithms are needed to reflect the disruption of larger scale neural networks held to be global effect of anesthetic drugs upon the brain. Such improvements will move pEEG devices closer to the goal of indicating true 'depth of anesthesia' [73].

\section{Compliance with Ethical Standards}

Conflict of Interest David A. Mulvey has received honoraria for teaching activities on behalf of Gwenagen Ltd., the UK distributor of the Narcotrend pEEG device, and is the President of the UK Society for Intravenous Anaesthesia. Peter Klepsch declares that he has no conflict of interest.

\section{References}

Papers of particular interest, published recently, have been highlighted as:

- Of importance

•- Of major importance

1. Fahy BG, Chau DF. The technology of processed electroencephalogram monitoring devices for assessment of depth of anesthesia. Anesth Analg. 2018;126(1):111-7.
2. Checketts MR, Alladi R, Ferguson F, et al. Recommendations for standards of monitoring during anaesthesia and recovery 2015: Association of Anaesthetists of Great Britain and Ireland. Anaesthesia. 2016;71(1):85-93.

3. Standards for basic anesthetic monitoring. American Society of Anesthesiologists: Committee on Standards and Practice Parameters. Available at: https://www.asahq.org/standards-andguidelines/standards-for-basic-anesthetic-monitoring. Last Amended: October 28, 2015 (accessed: 09/29/2020).

4. PS18 2017. Guideline on monitoring during anaesthesia. Australian and New Zealand College of Anaesthetists (ANZCA) Last amended December 2017. (accessed 09/29/2020).

5. Messina AG, Wang M, Ward MJ, et al. Anaesthetic interventions for prevention of awareness during surgery. Cochrane Database Syst Rev. 2016;10(10):CD007272. Published 2016 Oct 18. https://doi.org/10.1002/14651858.CD007272.pub2.

6. Lubke GH, Kerssens C, Phaf H, Sebel PS. Dependence of explicit and implicit memory on hypnotic state in trauma patients. Anesthesiology. 1999;90(3):670-80.

7. Linassi $\mathrm{F}$, Zanatta $\mathrm{P}$, Tellaroli $\mathrm{P}$, Ori $\mathrm{C}$, Carron $\mathrm{M}$. Isolated forearm technique: a meta-analysis of connected consciousness during different general anaesthesia regimens. Br J Anaesth. 2018;121(1): 198-209.

8. Coddens J. Memory and consciousness intertwingled. Br J Anaesth 2015; 115(5): p800-801, 800.

9. Avidan MS, Zhang L, Burnside BA, Finkel KJ, Searleman AC, Selvidge JA, et al. Anesthesia awareness and the bispectral index. N Engl J Med. 2008;358:1097-108.

10. Avidan MS, Jacobsohn E, Glick D, et al. for the BAG-RECALL Research Group. Prevention of intraoperative awareness in a highrisk surgical population. N Engl J Med. 2011;365:591-600.

11. Lewis SR, Pritchard MW, Fawcett LJ, Punjasawadwong Y. Bispectral index for improving intraoperative awareness and early postoperative recovery in adults. Cochrane Database Syst Rev. 2019;9(9):CD003843. https://doi.org/10.1002/14651858. CD003843.pub4 (accessed 09/01/2020).

12. Pandit JJ, Andrade J, Bogod DG, Hitchman JM, Jonker WR, Lucas $\mathrm{N}$, et al. The 5th National Audit Project (NAP5) on accidental awareness during general anaesthesia: summary of main findings and risk factors. Anaesthesia. 2014;69:1089-101.

13. Hajat Z, Ahmad N, Andrzejowski J. The role and limitations of EEG-based depth of anaesthesia monitoring in theatres and intensive care. Anaesthesia. 2017;72(Suppl. 1):38-47.

14. Nimmo AF, Absalom AR, Bagshaw O, Biswas A, Cook TM, Costello A, et al. Guidelines for the safe practice of total intravenous anaesthesia (TIVA). Anaesthesia. 2019;74(2):211-24.

15. Zhang C, Xu L, Ma YQ, Sun YX, Li YH, Zhang L, et al. Bispectral index monitoring prevent awareness during total intravenous anesthesia: a prospective, randomized, double-blinded, multi-center controlled trial. Chin Med J. 2011;124(22):3664-9.

16. Deiner S, Luo X, Silverstein J, Sano M. Can intraoperative processed EEG predict postoperative cognitive dysfunction in the elderly? Clin Ther. 2015;37(12):2700-5.

17. Avidan MS. A cricket with no legs cannot hear. Anaesthesia. 2020;75:567-9.

18. Dahaba AA. Different conditions that could result in the bispectral index indicating an incorrect hypnotic state. Anesth Analg. 2005;101:765-73 Summarizes the key limitations in use of the BIS device specifically, where index values do not coincide with clinically judged hypnotic state and could lead to misjudged alterations of management.

19. Messner M, Beese U, Romstöck J, Dinkel M, Tschaikowsky K. The bispectral index declines during neuromuscular block in fully awake persons. Anesth Analg. 2003;97(2):488-91. 
20. Schuller PJ, Newell S, Strickland PA, Barry JJ. Response of bispectral index to neuromuscular block in awake volunteers. $\mathrm{Br} \mathrm{J}$ Anaesth. 2015;115(Suppl 1):i95-i103.

21. Salgado-Seixas F, Pereira R, Machado H, Cavaleiro C. Misinterpretation and limitations of pEEG monitoring during multimodal general anesthesia: a case report. A \& A Practice. 2020;14(4):109-11.

22. Kaiser HA, Peus M, Leudi MM, et al. Frontal electroencephalogram reveals emergence-like brain activity occurring during transition periods in cardiac surgery. Br J Anaesth. 2020;125(3):291-7.

23. Russell IF. The ability of bispectral index to detect intra-operative wakefulness during total intravenous anaesthesia compared with the isolated forearm technique. Anaesthesia. 2013;68:502-11.

24. Russell IF. The ability of bispectral index to detect intra-operative wakefulness during isoflurane/air anaesthesia, compared with the isolated forearm technique. Anaesthesia. 2013;68:1010-20.

25. Schneider G, Wagner K, Reeker W, Hänel F, Werner C, Kochs E. Bispectral index (BIS) may not predict awareness reaction to intubation in surgical patients. J Neurosurg Anesthesiol. 2002;14:7-11.

26. Chan MT, Cheng BC, Lee TM, Gin T, CODA Trial Group. BISguided anesthesia decreases postoperative delirium and cognitive decline. J Neurosurg Anesthesiol. 2013;25(1):33-42.

27. Radtke FM, Franck M, Lendner J, Krüger S, Wernecke KD, Spies $\mathrm{CD}$. Monitoring depth of anaesthesia in a randomized trial decreases the rate of postoperative delirium but not postoperative cognitive dysfunction. Br J Anaesth. 2013;110(S1):i98-i105.

28. Fritz BA, Kalarickal PL, Maybrier HR, et al. Intraoperative electroencephalogram suppression predicts postoperative delirium. Anesth Analg. 2016; 122(1).

29. Punjasawadwong Y, Chau-in W, Laopaiboon M, et al. Processed electroencephalogram and evoked potential techniques for amelioration of postoperative delirium and cognitive dysfunction following non-cardiac and non-neurosurgical procedures in adults. Cochrane Database Syst Rev. 2018;5(5):CD011283. https://doi. org/10.1002/14651858.CD011283.pub2 (accessed 09/01/2020). Emphasize that many clinical trials lack the robust features needed to deliver firm and clear conclusions on the value of pEEG monitoring.

30. Bocskai T, Kovács M, Szakács Z, Gede N, Hegyi P, Varga G, et al. Is the bispectral index monitoring protective against postoperative cognitive decline? A systematic review with meta-analysis. PLoS One. 2020;15(2):e0229018. https://doi.org/10.1371/journal.pone. 0229018 (accessed 09/01/2020).

31. Sessler DI, Turan A, Stapelfeldt WH, Mascha EJ, Yang D, Farag E, et al. Triple-low alerts do not reduce mortality: a real-time randomized trial. Anesthesiology. 2019;130(1):72-82.

32. Short TG, Campbell D, Frampton C, Chan MTV, Myles PS, Corcoran TB, et al. Anaesthetic depth and complications after major surgery: an international, randomised controlled trial. Lancet. 2019;394(10212):1907-14.

33. Jildenstål PK, Hallén JL, Rawal N, Berggren L. Does depth of anesthesia influence postoperative cognitive dysfunction or Inflammatory response following major ENT surgery? J Anesth Clin Res. 2012; 3:6.

34. Sleigh JW, Gaskell A. Postoperative delirium: a minefield of markers and mediators. Anesthesiology. 2020;133:255-7 The title says it all-mandatory reading for users of pEEG.

35. Lindroth H, Sanders RD. Overlapping cognitive disintegration of anaesthesia and delirium. Br J Anaesth. 2018;121(1):193-6.

36. Curtis MS, Forman NA, Donovan AL, Whitlock EL. Postoperative delirium: why, what and how to confront it at your institution. Curr Opin Anesthesiol. 2020;33(5):668-73.

37. Berger M, Schenning KJ, Brown $\mathrm{CH}$, et al. for the Perioperative Neurotoxicity Working Group. Best practices for postoperative brain health: recommendations from the fifth international
Perioperative Neurotoxicity Working Group. Anesth Analg. 2018;127(6):1406-13.

38. Chan MT, Hedrick TL, Egan TD, García PS, Koch S, Purdon PL, Ramsay MA, Miller TE, McEvoy M, Gan TJ, Perioperative Quality Initiative (POQI) 6 Workgroup for the Perioperative Quality Initiative (POQI) 6 Workgroup. American Society for Enhanced Recovery and Perioperative Quality Initiative joint consensus statement on the role of neuromonitoring in perioperative outcomes: electroencephalography. Anesth Analg 2020; 130(5): 1278-1291.

39. Aldecoa C, Bettelli G, Bilotta F, Sanders RD, Audisio R, Borozdina A, et al. European Society of Anaesthesiology evidence-based and consensus-based guideline on postoperative delirium. Eur J Anaesthesiol. 2017;34:192-214.

40. Griffiths R, Beech F, Brown A, et al. Peri-operative care of the elderly 2014. Association of Anaesthetists of Great Britain and Ireland. Anaesthesia. 2014;69(Suppl 1):81-98. https://doi.org/10. 1111/anae.12524.

41. Nightingale CE, Margarson MP, Shearer E, et al. Peri-operative management of the obese surgical patient 2015. Association of Anaesthetists of Great Britain and Ireland \& Society for Obesity and Bariatric Anaesthesia. Anaesthesia. 2015, 70(7):859-76. https://doi.org/10.1111/anae.13101.

42. White S, Griffiths R, Baxter M, Beanland T, Cross J, Dhesi J, et al. Guidelines for the peri-operative care of people with dementia 2019. Guidelines from the Association of Anaesthetists of Great Britain and Ireland. Anaesthesia. 2019;74(3):357-72. https://doi. org/10.1111/anae.14530.

43. Loboa FA, Schraag S. Limitations of anaesthesia depth monitoring. Curr Opin Anesthesiol. 2011;24:657-66.

44. Constant I, Sabourdin N. The EEG signal: a window on the cortical brain activity. Paediatr Anaesth. 2012;22(6):539-52.

45. Voss L, Sleigh J. Monitoring consciousness: the current status of EEG-based depth of anaesthesia monitors. Best Pract Res Clin Anaesthesiol. 2007;21(3):313-25. https://doi.org/10.1016/j.bpa. 2007.04.003 Clinical Anaesthesiology 2007; 21(3): 313-325.

46. Scheinin A, Kallionpää RE, Li D, Kallioinen M, Kaisti K, Långsjö $\mathrm{J}$, et al. Differentiating drug-related and state-related effects of dexmedetomidine and propofol on the electroencephalogram. Anesthesiology. 2018;129(1):22-36.

47. Epstein RH, Maga JM, Mahla ME, Schwenk ES, Bloom MJ. Prevalence of discordant elevations of state entropy and bispectral index in patients at amnestic sevoflurane concentrations: a historical cohort study. Can J Anesth. 2018;65:512-21.

48. Kreuzer M. EEG based monitoring of general anesthesia: taking the next steps. Front Comput Neurosci. 2017;22(11):56. https://doi.org/ 10.3389/fncom.2017.00056.

49. Bennett C, Voss LJ, Barnard JP, Sleigh JW. Practical use of the raw electroencephalogram waveform during general anesthesia: the art and science. Anesth Analg. 2009;109(2):539-50.

50. Purdon PL, Sampson A, Pavone KJ, Brown EN. Clinical electroencephalography for anesthesiologists part 1: background and basic signatures. Anesthesiology. 2015;123(4):937-60 An excellent review of the biophysics of electroencephalography and the neurophysiology of signatures from three intravenous and four inhaled anesthetic agents.

51. Brown EN, Purdon PL, Akeju O, An J. Using EEG markers to make inferences about anaesthetic-induced altered states of arousal. Br J Anaesth. 2018;121(1):325-7.

$52 . \bullet$ Kim MC, Fricchione GL, Brown EN, Akeju O. Role of electroencephalogram oscillations and the spectrogram in monitoring anaesthesia. BJA Education. 2020;20(5):166-72 Up-to-date article reinforcing the need to recognize the signatures of key anesthetic hypnotics from their raw EEG and DSA signatures and of the effect of aging upon these parameters.

53. Hagihira S. Brain mechanisms during course of anesthesia: what we know from EEG changes during induction and recovery. Front Sys 
Nerosci. 2017;11:39. https://doi.org/10.3389/fnsys.2017.00039 (accessed 09/01/2020).

54. Hagihira S. Changes in the electroencephalogram during anaesthesia and their physiological basis. Br J Anaesth. 2015;115(Suppl 1): i27-31.

55. EN Brown et al., Monitoring brain state during general anesthesia and sedation, in Miller's Anesthesia 8th edition, 2014, Elsevier, ISBN-10: 0702052833

56. Barnard JP, Bennett C, Voss LJ, Sleigh JW. Can anaesthetists be taught to interpret the effects of general anaesthesia on the electroencephalogram? Comparison of performance with the BIS and spectral entropy. Br J Anaesth. 2007;99(4):532-7.

57. Bottros MM, Palanca BJ, Mashour GA, et al. Estimation of the bispectral index by anesthesiologists: an inverse Turing test. Anesthesiology. 2011;114(5):1093-101.

58.• Bombardieri AM, Wildes TS, Stevens T, et al. Practical training of anesthesia clinicians in electroencephalogram-based determination of hypnotic depth of general anesthesia. Anesth Analg. 2020;130(3):777-86 Demonstrates that anesthesiologists can easily expand their skill set to look beyond the index number displayed by their pEEG device.

59. Purdon PL, Pavone KJ, Akeju O, Smith AC, Sampson AL, Lee J, et al. The ageing brain: age-dependent changes in the electroencephalogram during propofol and sevoflurane general anaesthesia. Br J Anaesth. 2015;115(Suppl 1):i46-57.

60. Schultz A, Grouven U, Zander I, Beger FA, Siedenberg M, Schultz B. Age-related effects in the EEG during propofol anaesthesia. Acta Anaesthesiol Scand. 2004;48:27-34.

61. Kreuzer M, Stern MA, Hight D, Berger S, Schneider G, Sleigh JW, et al. Spectral and entropic features are altered by age in the electroencephalogram in patients under sevoflurane anesthesia. Anesthesiology. 2020;132(5):1003-16.

62. Gaskell AL, Hight DF, Winders J, et al. Frontal alpha-delta EEG does not preclude volitional response during anaesthesia: prospective cohort study of the isolated forearm technique. Br J Anaesth. 2017;119(4):664-73.

63. Shao YR, Kahali P, Houle TT, Deng H. Low frontal alpha power is associated with the propensity for burst suppression: an encephalogram phenotype for a "vulnerable brain". Anesth Analg. 2020. https://doi.org/10.1213/ANE.0000000000004781 Online ahead of print. An interesting viewpoint and one that is worthy of further examination.
64. Berger M, Mark J, Kreuzer M. Of parachutes, speedometers, and EEG: what evidence do we need to use devices and monitors? Anesth Analg. 2020;130(5):1274-7.

65. Sun Y, MD, Ye F, Wang J, et al. Electroencephalography-guided anesthetic delivery for preventing postoperative delirium in adults: an updated meta-analysis. Anesth Analg 2020; 131(3): 712-718.

66. Wildes TS, Mickle AM, Abdallah AB, et al. for ENGAGES Research Group. Effect of electroencephalography-guided anesthetic administration on postoperative delirium among older adults undergoing major surgery: the ENGAGES randomized clinical trial. JAMA. 2019;321(5):473-83.

67. Koch S, Radtke F, Spies C. A call for a more rigorous screening of postoperative delirium. Ann Transl Med. 2019;7(Suppl 6):S192.

68. Pasin L, Nardelli P, Pintaudi M, Greco M, Zambon M, Cabrini L, et al. Closed-loop delivery systems versus manually controlled administration of total IV anesthesia: a meta-analysis of randomized clinical trials. Anesth Analg. 2017;124(2):456-64.

69. Joosten A, Rinehart J, Bardaji A, van der Linden P, Jame V, van Obbergh L, et al. Anesthetic management using multiple closedloop systems and delayed neurocognitive recovery: a randomized controlled trial. Anesthesiology. 2020;132(2):253-66.

70. Rubulotta F, Soliman-Aboumarie H, Filbey K, Geldner G, Kuck K, Ganau M, et al. Technologies to optimize the care of severe COVID-19 patients for health care providers challenged by limited resources. Anesth Analg. 2020;131(2):351-64.

71. Shetty RM, Bellini A, Wijayatilake DS, et al. BIS monitoring versus clinical assessment for sedation in mechanically ventilated adults in the intensive care unit and its impact on clinical outcomes and resource utilization. Cochrane Database Syst Rev. 2018;2(2): CD011240. https://doi.org/10.1002/14651858.CD011240.pub2 (accessed 09/01/2020).

72. Dahaba AA. Thinking outside the box. Off-label use of bispectral index within context and limitations for conditions other than depth of anesthesia. Minerva Anestesiol. 2019;85(2):189-93.

73. Hudetz AG, Mashour GA. Disconnecting consciousness: is there a common anesthetic end-point? Anesth Analg. 2016;123(5):122840 .

Publisher's Note Springer Nature remains neutral with regard to jurisdictional claims in published maps and institutional affiliations. 